Article

Paradigms in Geography: Issues and Opportunities

\author{
Journal of Development Economics and \\ Management Research Studies (JDMS), \\ A Peer Reviewed Open Access \\ International Journal \\ ISSN: 25825119 (Online) \\ Crossref Prefix No: 10.53422 \\ 08(10), 1-15, October-December, 2021 \\ @ Center for Development Economic \\ Studies (CDES) \\ Reprints and permissions \\ http://www.cdes.org.in/ \\ http://www.cdes.org.in/journal/
}

\title{
PARADIGMS IN GEOGRAPHY: ISSUES AND OPPORTUNITIES
}

\section{T. Vasantha Kumaran ${ }^{1}$}

\begin{abstract}
Geography is what geographers do. Do I do geography? Yes, I do. What geography do I then do and how? The focus of my paper is on the Paradigms in Geography, the issues and opportunities. The paper discusses the meanings of paradigms in geography and also practices, issues and opportunities they offer such that an individual teacher, researcher and practitioner of geography could speak of her/his paradigms and those of her/his collaborators in the enterprise of 'knowing-doing geography'.

\section{My Geographies}

My geography is principally one that tries to understand perceptible phenomena which could be explained towards making a theory or could be validated by using a theoretical underpinning. Most often I try to understand the phenomena, whatever may be their descriptions, the best I can by explaining 'how they work' and 'to what end'. There is, at the back of mind, a sense of the theory of relationships and an urge to understand their (phenomena's) appearance, inner logic, possible developments, and rational management the four levels of understanding defined as description (of facts), explanation (of relationships), prediction (of possibilities) and prescription (of goals).
\end{abstract}

\section{Science and Reasoning}

What is science? You see something happen, you ask why?You want to make something happen, you ask how? So, science is a tool for answering why and how. And Science is a tool for telling you what works! How do you know if your theory (idea, model, hypothesis) is right?You can test it! That is how you come to know your theory is right (or wrong). A scientific theory must do two things: (a) Explain what is seen; and (b) Predict what will happen in the future. It is my reasoning of geography that brings about the paradigms I practice and write about.

For me, a paradigm is a constellation of ideas, which gives me issues to deal with, opportunities to probe them, and if I ever succeed in my efforts then I find solutions

\footnotetext{
${ }^{1}$ Formerly Professor and Head of Geography, University of Madras, Chennai 600 005, India.
} 
for some of the problems I deal with in my everyday life, in space and time I live and have a 'lived experience'. My paradigms give me problems as well as solutions, for solutions are within the problems and in those who create/make problems.

Moreoftenthan not I explain things, rather than predict, which I rarely do, if ever. But there is this prediction, always at the back of mind, for without it I cannot prescribe, for prescribing solutions for the problems I study is my business as a teacher, researcher and practitioner.

\section{Paradigms in Geography}

A paradigm is an implicit body of intertwined theories and methodologies that permits selection, evaluation and criticism (Thomas Kuhn, 1949). The generally accepted perspective of a particular discipline at a given time, in popular use, may be a paradigm. In geography, as in other disciplines, paradigms establish the rules and boundaries for the way we see things. But these keep changing over time and with increasing knowledge and improving means of doing things. There are always paradigm shifts, which are significant changes in thinking that result in completely changed views or outlook, a radical replacement sometimes of a way of thinking or organizing: old ways get replaced by new ways.

Geography is Multi-Paradigmatic, Integrated and Multi-disciplinary

Geography is multi-paradigmatic, being an integrated, multidisciplinary discipline. There are two major types of paradigm, in geography, as shown below. As the intention here is only to indicate that the geographical paradigms have changed and there were shifts, no elaborate discussion is attempted on the capitalist and radical paradigms. Suffice it to say that the two have been in practice, for a long time and also now.

The Two Major Types of Paradigm in Geography are:

- Capitalist Paradigm

- Free Market, Anti-Collectivist

- Social Darwinism, Neo-Malthusian

- Liberal Interventionists

- Radical Paradigm

- Dependency Analysts

- Marxists

But I am no radical geographer (neither dependency analyst nor Marxist). I am an Establishment Geographer and I follow what most others practising geography - the Geographers who are followers rather than leaders - know and do: My knowing-and-doing is restricted to paradigms of normal geographers, not revolutionary geographers.

There have been several paradigms in the history of geography and they are as follows:

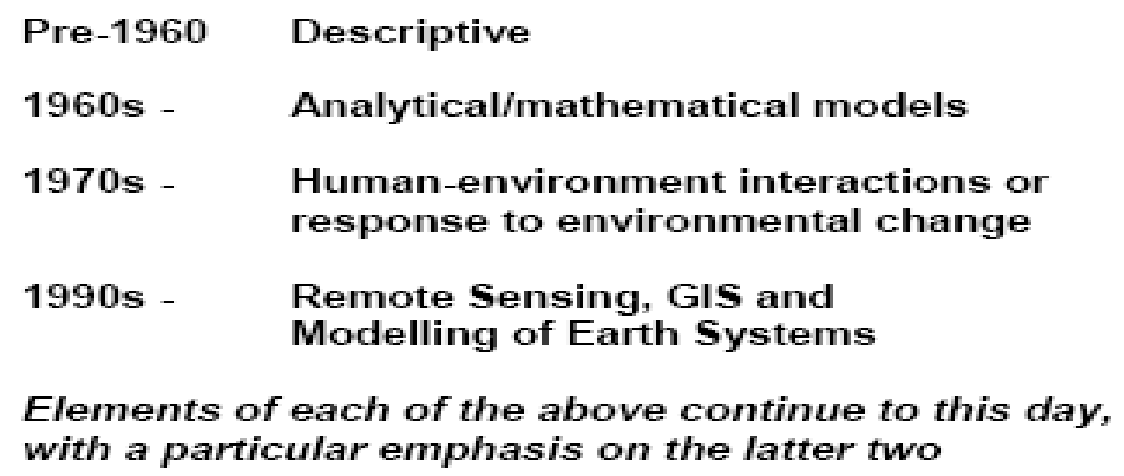

Elements of each of the above continue to this day, with a particular emphasis on the latter two

Also, when we look closely at what has been happening in geographical research in the last few years, the overwhelming paradigm of the last two decades has been that of sustainable development. The strands are:

O The 1990s -

One world, Our Common Future, Sustainable Development

O The 2000s -

Sustainable development - Agenda 21 to Action 21, MDGs 


\section{O The 2010s - $\quad$ Sustainable Development Goals}

Being a science concerned with the environment and development, geography has taken on the task of researching sustainable development in a big way. Case studies discussed here are a part of this effort, with participatory approaches for field-to-theory and community engagement.

I speak of the issues that I have dealt with in my research and the opportunities I have had to both explain and to a certain extent predict and prescribe. I have been a complete geographer, because of what I have known and what I have done: knowing-doing-knowing has been my job.

Keywords: Geography, paradigms, imagination, capitalist and radical.

\section{PARADIGMS IN GEOGRAPHY: ISSUES AND OPPORTUNITIES}

To many people geography is a body of knowledge whereas to others it is anacademic discipline that studies that subject matter.

- Ron Johnston (Geographer)

God has placed us on the earth and below the skies; so that in lowering our eyeswe might inspect the earth, while in raising them we might contemplate theheavens. Looking upwards and attentively considering this admirable machine ofthe world we become astronomers. Lowering our gaze towards the earth, andmaking a measure of its extent, we are geographers. Using these twosciences, man renders himself a worthy inhabitant of the world.

- HenryHondius (Cosmographer)

When the wind of change blows, some build walls, others build windmills (当风向改变时,有的人筑墙, 有的人造风车).

\section{Introduction}

- Chinese proverb

Geography is a world discipline, connecting popular andacademic geographical imaginations (Bonnett, 2003, 2008). This paper is about paradigms in geography, issues and opportunities. It offershowever no more than a preface to producing that 'little knowledge' on paradigms ingeography,with an overview of the nature of the geographical paradigms and their typical meanings and implications, including the issues and opportunities they provide for geographers, their practitioners, to deal with and resolve and take on in their teaching and research.Much more can be done researching the nature of the popular geographicalimaginations and the paradigms that they promote and the techniques that they deploy, not only overtime but also over space, for geography is space-time discipline.

In contemporary times, geography to many people, particularly lay people and nongeographers, means a subject concerned with the world,emphasising maps, natural history, landforms, and landscapes, plus basic informationsuch as capital city names and river lengths - sometimes called 'capes and baysgeography'.To others, basically to those who have studied it in further and higher education, it is a discipline that provides understanding, appreciation, evenexplanation, of aspects of the world through practices bridging the humanities, socialsciences, and natural sciences.I am sure that how academic geographers practice their discipline undoubtedlyinfluences how others (politicians and policy-makers) view it, withpotential implications for attitudes towards the discipline, perhaps even its publicsupport and funding. It certainly means thatacademic geographers are not using popular media to inform a wider publicabout their work and geographical imaginations, and perhaps, too, that 
they considertransmitting their understanding of the world through such media either unnecessaryor unbecoming. And if they do, they may do very rarely.

Now, before getting to the point of defining, describing and elaborating on the paradigms in geography, it is important to focus on a few aspects of geography that would help us to understand them (paradigms), the issues and opportunities they offer, better. Let me introduce, for a start, some ideas on the geographical imaginations of the practitioners of geography and also understanding in geography. Note that, to understand the nature and perspectives on the nature of geography, I recommend a careful reading of some classical works in geography by Hartshorne $(1939,1959)$, Harvey $(1969,1984)$, Haggett $(1972,1990)$ and Johnston $(2003,2004)$. If you wish to give your readers the best reading you could, then I believe that photographs, maps, charts and a wealth of well-researched data must be provided to backup every point you make in your research papers. Surely that is the kindof thing we should be striving for in our writings to make geography popular and widely read, that is, focused research to answer the intricaciesof a larger problem. The great value of geography is its capacity, like history, to describeand offer coherent explanations (Geographical, October 2007, 107).

\section{Geographical Imaginations}

Space stretches boundlessly and inconceivably, and withinit, the planetary globe is an insignificant speck whose only centrality is thatattributed to it by human imagination.

\section{Cosgrove, D. June 2005, Hettner Lecture I, UCLA}

Geographical imagination is a sensitivitytowards the significance of place and space,landscape and nature, in the constitutionand conduct of life on Earth. It is by no means theexclusive preserve of the academic disciplineof geography, though. In the 1960s, it was portrayedas a persistent and universal instinct of (humankind). The geographical imaginations were a response to places andlandscapes, above all to their co-mingling of'culture' and 'nature', that 'calls into action our powers of sympathetic insight and imaginative understanding' and whose rendering'is a creative art' (Cosgrove, 2006). Cosgrove (2006) has examined the roles that vision and imagination have played in shaping material and represented landscapes at scales ranging from the local and regional to the global and cosmic. Others, on the other hand, have emphasisedart and, by implication,on geography's place among the humanities; and theirs havebeen in part a critical response to the reformulationof the discipline as a spatial science (see also Castree, 2001). In geographical imaginations, it is vitally important to preserve $a$ direct experience oflandscape through the art of geographicaldescription.

Geographical imaginations have been afertile focus of research, especially in cultural, social and historical geography(Gregory, 1995; Kasbarian, 1996), as well as in more contemporary political andcultural analyses (McFarlane, 2004; Changand Lim, 2004). Eleven main themes, for a sample of themes, stand out in the analysis of the geographical imaginations of the geographers.

They are:
$\checkmark$ Place;
- Scale;
- Location; 
Function;

- Social, economic, environmental and political dimensions;

Tourism;

Local-global links;

Culture and social injustice;

- Awe and wonder;

Fragility of environments; and

- Sustainable development.

They give rise to questions such as:

Where are the people?

Where am I in this?

What has it to do with me?

Why should I care about this place?

- And several others

Answers to these, and several other questions, lead one to geographical imaginations. In this respect, autobiographies are a history of geographies: 'Dreams from my father' of President Barak Obama is a text of geographical imaginations, speaking of the race (AfroAmerican) and space in the United States of America. Similarly, the autobiography of Jawaharlal Nehru, the first Prime Minister of Independent of India,is a text of geographical imagination as well, for there are answers to questions Nehru has raised as to the discovery of India. To illustrate other such geographical imaginations, I quote a passage from Cook and Crang (1996: 41) which appears as The Idea for a paper in Antipode (Cook et al., 2014: 642):

...if we accept that geographical knowledges through which commodity systems are imagined and acted upon from within are fragmentary, multiple, contradictory, inconsistent and, often, downright hypocritical, then the power of a text which deals with these knowledges comes not from smoothing them out, but through juxtaposing and montaging them...so that audiences can work their way through them and, along the way, inject and make their own critical knowledges out of them.

\section{Understanding in Geography}

Geography is about the understanding of the people, places and environmentsof our world, the processes by which they are changing, and theinterconnections between them, both locally and globally.

- Geographical (Magazine), UK.

Geography is what geographers do. Do I do geography? Yes, I do. What geography do I then do and how? This is one of the focuses of this paper as well. My geography is principally one that tries to understand perceptible phenomena which could be explained towards making a theory or could be validated by using a theoretical underpinning (Figure 1). Most often I try to understand the phenomena, whatever may be their descriptions, the best I can by explaining 'how they work' and 'to what end'. There is, at the back of my mind, a sense of the theory of relationships and an urge to understand their (phenomena's) appearance, inner logic, possible developments, and rational management - the four levels of understanding defined as description (of facts), explanation (of relationships), prediction (of possibilities) and prescription (of goals) as shown below. 


\section{Figure 1: Understanding}

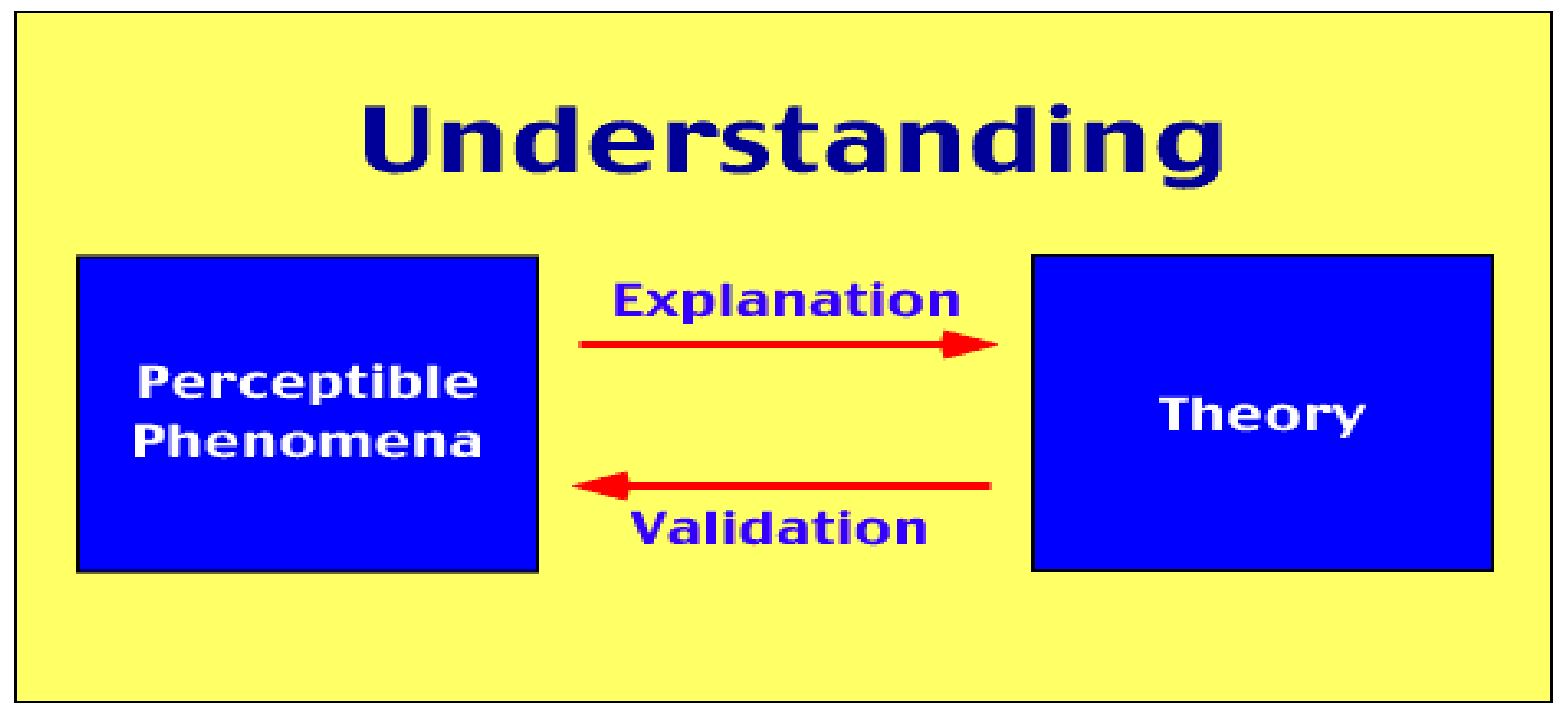

Levels of Understanding: The best way to understand the international context of what geography is and where is it anchored is to review the four functions of research but let me not proceed on it except by showing what the four functions are:

1. Describea phenomenon that is of particular interest to us.

2. Explain the relationships that exist in the key variables in the phenomenon of interest to us.

3. Predictthe circumstances under which the phenomenon will/will not occur (for example, using hypothesis to guide the search effort).

4. Control (or Prescribe) especially to intervene in a situation to produce a more positive outcome.

It is of some importance to know what is being understood, however. Is it simply a phenomenon or two we are trying to understand or a whole constellation of ideas emerging from what we consider the geographical paradigm of the present? And I do realize geography is very past-oriented, and there is little emphasis on the future of management. This situation has been changing ever so slowly in the last three decades. A look at the changing, shifting paradigms in geography tells us 'what we have been and are concerned with' in the study of geography. As a practitioner of geography (I do believe what I do is geography), I am currently learning, teaching and researching the paradigm of the present.

What is a paradigm?

To be accepted as a paradigm, atheory must seem better than its competitors, butit need not, and in fact never does, explain all the facts with which it canbe confronted.

Thomas S. Kuhn, the Structure of Scientific Revolutions, Volume II (2): 17.

A paradigm is an implicit body of intertwined theories and methodologies that permits selection, evaluation and criticism (Thomas Kuhn, 1949). The generally accepted perspective of a particular discipline at a given time, in popular use, may be a paradigm.

A paradigm is an explanatory framework - it provides a statement of the most appropriate way of studying an issue (It is a Term famously developed by Thomas S. Kuhn in The Structure of Scientific Revolutions, 1962). 
In geography, as in other disciplines, paradigms establish the rules and boundaries for the way we see things. But these keep changing over time and with increasing knowledge and improving means of doing things. There are always paradigm shifts, which are significant changes in thinking that result in a completely changed view or outlook, a radical replacement sometimes of a way of thinking or organizing: old ways get replaced by new ways (see Figure 2, which is self-explanatory).

Figure 2

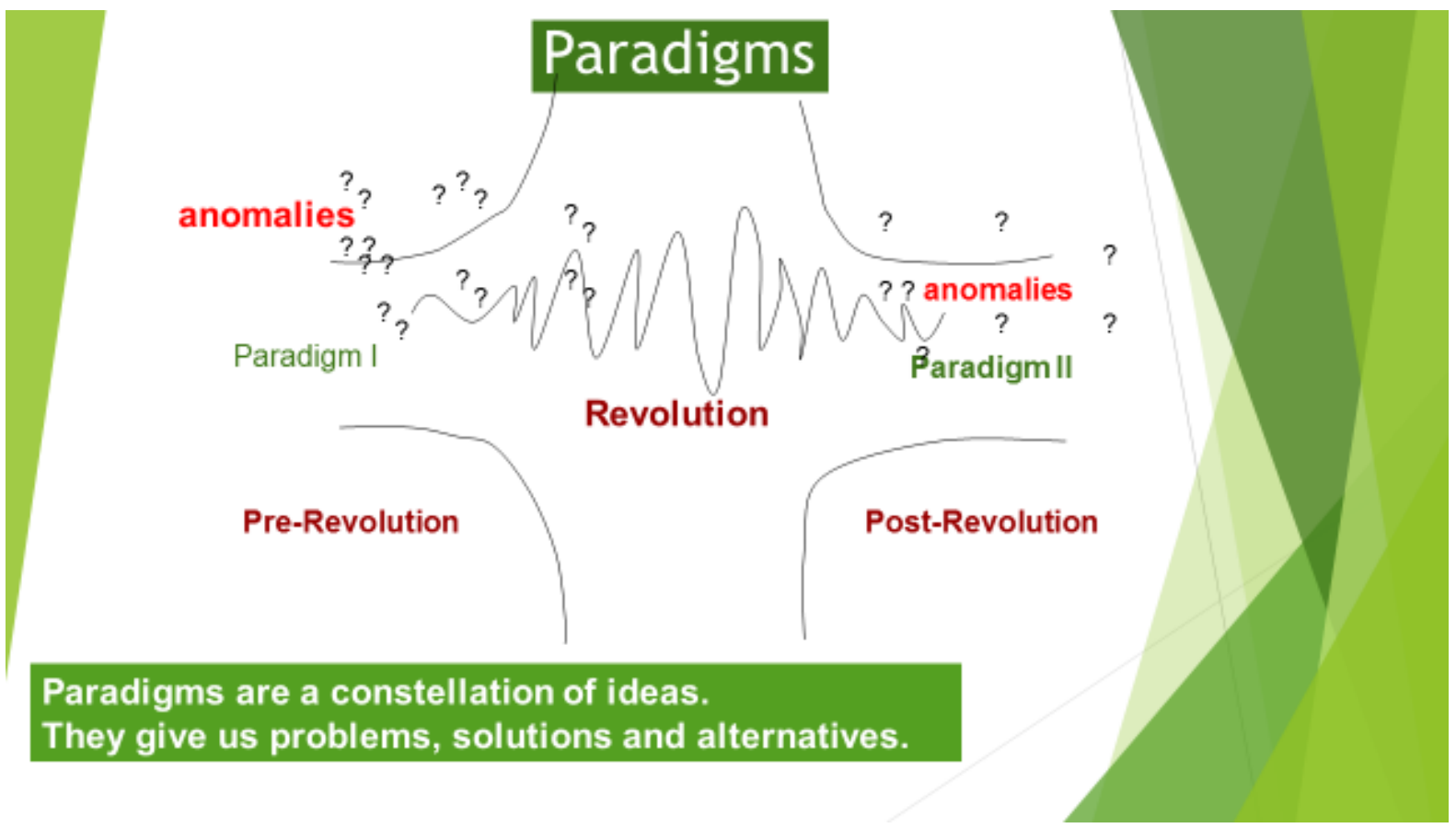

Paradigms are however models with general applicability which attempt to describe "reality" as science understands it. And the anomalies are the Elements of reality unexplained by scientific models. Paradigm is any or all of the following as well:

- The frame of reference;

- Model for understanding;

- Shapes what we see;

- Shapes how we understand; and

- Resistances to change.

In social sciences, paradigms are however unique and they are rarely discarded, for example, Copernicus heliocentric universe vs Ptolemaic model. But paradigm shifts are possible. I am not talking about the early history of paradigm-making in geography, because as geographers we are all very familiar with the paradigms of the $18^{\text {th }}, 19^{\text {th }}$, and early $20^{\text {th }}$ centuries. Hence I speak of paradigms in the paper from the 1960s, as they are more important for us practitioners of geography today, as we continue the traditions of the paradigms since the 1960s even now.

Geography is undoubtedly multi-paradigmatic, being an integrated, multidisciplinary discipline. There are two major types of paradigm, in geography, as shown below. As the intention here is only to indicate that the geographical paradigms have changed and there 
were shifts, no elaborate discussion is attempted on the capitalist and radical paradigms. Suffice it to say that the two have been in practice, for a long time and also now, and will be in the foreseeable future of the $21^{\text {st }}$ century as well.

- Capitalist Paradigm

- Free Market, Anti-Collectivist

- Social Darwinism, Neo-Malthusian

- Liberal Interventionists

- Radical Paradigm

- Dependency Analysts

- Marxists

There have been several paradigms in the history of geography and they are as follows:

- Pre-1960 Descriptive

- 1960s - Analytical / Mathematical models

- 1970s - Humans-Environment Interactions or Response to Environmental Change

- 1980s - $\quad$ Remote Sensing, GIS and Modelling of Earth Systems

Elements of each of the above continue to this day, with a particular emphasis on the latter two paradigms. Also, when we look closely at what has been happening in geographical research in the last few years, the overwhelming paradigm of the last two decades has been that of sustainable development. The strands are:

1990s -One world, Our Common Future, Sustainable Development

2000s -Sustainable development - Agenda 21 to Action 21

2010s -Big Data - data mining and all that it entails

Being a science concerned with the environment and development, geography has taken on the task of researching sustainable development in a big way. Case studies discussed here are but a few examples, of my own and the collaborative researches I have been a valuable part of, with a characteristic blend of quantitative as well as qualitative, but importantly ofparticipatory approaches for field-to-theory and community engagement. About them, a little later but now to models, theories and empirical studies, very briefly.

\section{Models, Theories and Empirical Studies}

We must recognize how very limited in bothscope and precision a paradigm can be at the time of its firstappearance. Paradigms gain their status because they are moresuccessful than their competitors in solving a few problems that the group of practitioners has come to recognize as acute. To be moresuccessful is not, however, to be either completely successful with asingle problem or notably successful with any large number.

- Thomas S. Kuhn, The Structure of Scientific Revolutions, Volume II (2): 23.

Figure 3 presents a general framework providing a useful context for relating my learning, teaching and researching enterprises. The 'continua of categorizing models' has three continua: the first is the continuum defined in most general terms as running from purely theoretical to purely empirical; the second is the continuum of simple to complex, and the third is that of positive to normative. Theoretical models are often constructed to serve as explanatory tools. The results from them are often generalizable to a range of research applications. In contrast, empirical models are often designed to closely match the 
details of a particular case study. As such, their conclusions are often specific to that case. However, both theoretical and empirical models potentially serve as exploratory tools.

Figure 3: Continua of Categorizing Models

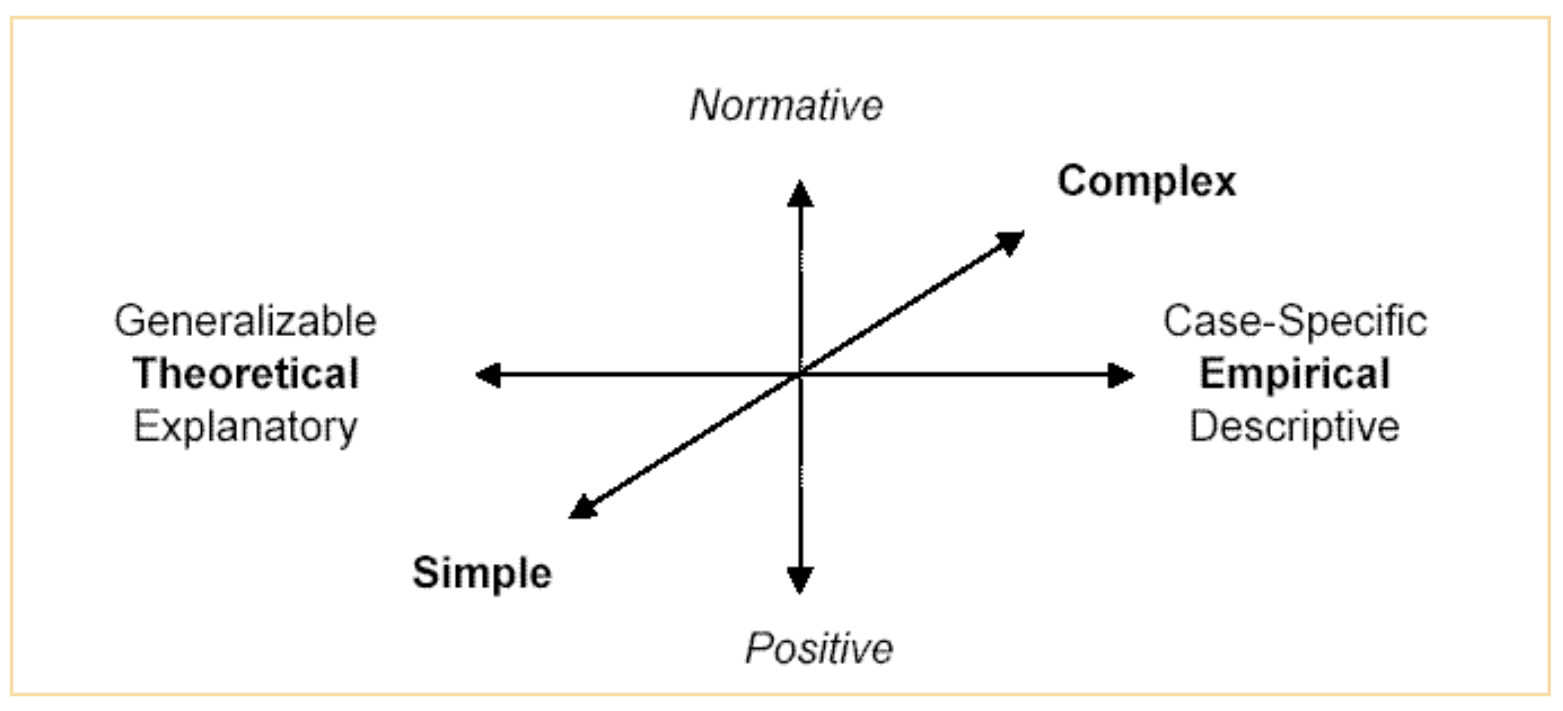

Theoretical models are often deductive, for they use a logical procedure to derive some very specific results from basic and unquestioned assumptions (axioms).

Inductive methods filter patterns from empirical data to identify some general laws behind them.

Normative (describing how reality could or should be under ideal circumstances)

Positive (describing links between mechanisms and outcomes without judgment as to fitness or appropriateness).

The simple to the complex continuum is an important one and is distinct from the theoretical/empirical continuum. While a theoretical model may be relatively complex, an empirical model may be quite simple. There is an ever-present danger of building too much complexity into any model, resulting in difficulty in understanding how processes drive outcomes. On the other hand, the normative describes how reality could or should be under ideal circumstances while the positive describes the links between mechanisms and outcomes without judgment as to fitness or appropriateness.

I think there is no need to go any further than this, for the present exposition of paradigms, as I have brought in the significant elements of the backdrop that has guided my work, individual as well as collaborative, in the last 40 years (1974-2014). Suffice it to say, these are important in evaluating what I do as part of my scholarly work. In the light of this backdrop, I understand which level is geography at, which level is my subfield (geography of sustainable development, for example) at, and, most importantly, which level is am I at. I am sure that I operate, in my learning, teaching and researching, at various levels and along all three continua, severally and also all at once.

As a geographer, knowing and doing geography, I must make a statement as to whether I define and redefine geography for myself as I continue with my work. I believe I do. Often, my definitions and my meanings are impinged upon by the definitions and meanings of colleagues and fellow researchers I work with. I am very confidently 
international. What I think influences my international colleagues and what they do influence and shape mine. I am already a global player, playing with other global players. We are so networked - wired to our brains and thinking - I am very $\boldsymbol{G L} \boldsymbol{O B} \boldsymbol{A} \boldsymbol{L}$, even as I am anchored in my LOCAL. I am a local-global practitioner of geography, thinking globally and acting locally, as sustainable development as a field of study demands, for example. Let us now get on with how I am redefining geography for myself and my international colleagues, through my paradigms, the paradigms I worked with in the last four decades, as shown in Figure 4.

\section{The Scholarship of Engagement}

Often a paradigm developed for one set of phenomena isambiguous in its application to other closely related ones. Thenexperiments are necessary to choose among the alternative ways ofapplying the paradigm to the new area of interest.

-Thomas S. Kuhn, The Structure of Scientific Revolutions, Volume II (2): 29.

To become active participants in culture, we need to do creative work, learning through discussions and critiques to self-organize, self-monitor and self-evaluate. What do we, as a people and a community, see in such venues? We need an education that prepares us to create a culture that provides the goods we most want. We need to ensure that the catchwords "community" and "cooperation" are more than buzzwords. We need the community itself to be the subject of serious study through an education centered in local institutions that serve community purposes.

If we are to shape our destiny we indeed need an "engagement" that would take us beyond all those pre-formulated experiences, shaped for us by others. We need to observe and take notes, making the first drafts of culture. We need direct encounters with nature, with historic sites, and with people who do and have done real work. In other words, we need "community engagement", an engagement that takes our sense of place seriously. And, indeed, we have not yet found the best way to live in Chennai or Mysuru. But our culture is still young and the future beckons, as vast and deep as we dare to see.

Figure 4

\section{Paradigms of my work-research 1974-2014}

- Marriage migration (Bavalalu, Hunsur study 1974) Distance Decay

Spatial Diffusion and Monte Carlo Simulation (Distance Decay) (PhD 1974-80)

Cultural Ecology Paradigm (Kollihills, Tribal agriculture study 1980-83)

Provider-User Spatial Behaviour Paradigm - Healthcare in Thanjavur 1984-86

Participatory Action Research Paradigm (Water Users' Association 1988-98)

Community Action Planning Paradigm (Desertification 1995; 1998-2001)

Food Security and Traditional Ecological Knowledge (Kollihills Revisited 2001-03)

Adaptive Ecosystem Management Paradigm (Chennai Slums 2001-07)

Community Engagement, Self-Help (Groups) Paradigm (2007-09)

Ethno-Geographical Paradigm (1998-2010)

Social Vulnerability - Health Vulnerability, Coping and Adaptation (2007-10)

EIA-SIA of Emerging-Polluting Captive Power Industries (2009-11)

- Big Data and Data Mining (Property-Utility Mapping, Street Vendors, Homeless Mapping and Surveys 2011-14) 
There is the changing context and policy environment brought on first by the paradigm of sustainable development (since 1987), and then by the process of globalization (the MNCs, TNCs, the IT companies) and the push towards recognizing that regions matter (for example, India and China matter in the world affairs). What happens in our region, in our country and in our diverse cultures, is changing the nation's quality of life. There is a sea change since globalization or from when it has begun to affect our lives, in rural and urban areas. In Chennai, I feel the change and see the change, in my household where 3 of the members are in IT professions and my neighborhood when I see loads of young people commuting by 'air buses' right through the day and more so in the night. While in the (research study) field sites, I have my mobile connecting me with not only people and places in India but also abroad. The rural people wield power over so much of the world - a friend in a Theni (Tamil Nadu) village has a son working in Malaysia - information flybys are a regular occurrence. Money from Malaysia has changed the entire household of my friend. I have another friend here who is an organic farmer. He gets calls from Singapore enquiring about his farming methods.

One of the diversification elements is the increasing engagement of (international) universities like mine (University of Madras) and the universities in Canada, UK, Australia and Germany with our communities: since 1998, my Canadian colleagues and interns have made more than 100 trips; Australians have made 30 plus trips, the UK have made 56 plus trips and Germans have made nearly 40 trips to Chennai and field sites. This engagement involves genuine partnerships between my study communities and several universities. This has also helped with addressing perceived natural (desertification), social (caste, class, oppression) and economic (poor agriculture) problems with creativity and new insights (Kumaran, Hyma and Wood, 2004).

Our researches into (a) environmental restoration from the clutches of desertification in Theni villages, (b) biodiversity and food security through indigenous knowledge of the Malayali tribe of the Kollihills, (c) environment and health of the Chennai slums, (d) posttsunami rehabilitation of the slum people of Chennai, (e) livelihood trajectories, entitlements and capacities of the peri-urban people of Medavakkam and (f) the proposed research on health vulnerability of Chennai are all based on case study analysis.

The extent of connectivity between higher education and local, regional, rural and urban community priorities so far has been project-specific. On the other hand, we have at least one intern who worked on the Theni and Kollihills projects who is currently involved in community-driven initiatives of water resources consolidation in a Theni village and total sanitation in several villages about Theni. His engagement with the communities and his continued relationships with the international universities is proving that the engagement is not just a romantic, narrow project-specific engagement but rather one predicated on rigorous analysis of achievements on a whole-of-university and whole-of-community basis. In January 2006, the Australians visited the Theni and Kollihills villages, peri-urban Medavakkam and Chennai slums to gain an appreciation of the long-term research enterprise that has been on for 25 years of community engagement by the University of Madras.

There has been an attempt on our part towards examining the collective social experiences of rural and urban communities and localities and pass them on to the younger generation in a learning-teaching environment in both the regular stream and the distant education stream. The online, distance education program on Sustainable Development in partnership with Staffordshire University has made possible the dissemination of these experiences throughout the country and abroad. The scholarship of community engagement 
and culture, manifested in all our collaborative research programs, is, in reality, learning from the 'Margins', because the research enterprise has done much with the people on the edge of life, in slums of Chennai and the villages of Kollihills and Theni.

The partnerships of the research enterprise have provided a space where issues like identity difference and diversity are not submerged in a homogenizing educational tradition. Rather space is opened within which the nature and extent of globalization itself can be debated. This space is now being utilized as a discursive practice, a way of thinking, speaking and acting that interacts with changes in socio-economic and cultural structures.

I am now able to negotiate my perspective from conversations with those who came from different places, experiences, disciplines, locales and histories within a space that appeared to be marginal. Yet it has now become my 'inner space', as productive as any space can be in the circumstances. Let me just elaborate on one case study, and be done with it.

\section{Adaptive Ecosystem Approach to Environment and Health in Chennai}

Even in the mathematical sciences, thereare also theoretical problems of paradigm articulation; and duringperiods when scientific development is predominantly qualitative, theseproblems dominate. Some of the problems, in both the morequantitative and more qualitative sciences, aim simply at clarification byreformulation.

-Thomas S. Kuhn, The Structure of Scientific Revolutions, Volume II (2): 33.

The working session involved the collaborative development of a diagrammatic expression of the problem. The techniques for developing and using such "rich pictures" are borrowed from Soft Systems Methodology. For this exercise, participants chose to express the environment and health situation of slum areas. By this point in the workshop (midafternoon of the first day) slums and slum dwellers had already arisen as a primary theme. The rich picture was constructed by facilitating a discussion of important environmental and health relationships, actors and elements in slum areas, and recording these on contiguous large sheets of paper (instead of a blackboard, or whiteboard). Figure 5 below is a redrawing of the rich picture developed during one such workshop.

This rich picture expression of a problematic situation focused on environment and health in slums does not portray all possible actors, elements and relationships. Nor does it represent all possible perspectives (such as that of slum dwellers themselves). Yet, it does begin to portray the degree of complication in the situation and highlights some important clusters of (via henchmen) the Corporation of Chennai to provide such civic amenities to their protected slums. Access to slum dwellers was seen to be controlled by slum leaders and "Slum Lords."

Issues that participants identified as important were wide-ranging but seemed to accent slums and water pollution. There were indeed 70 problems the workshop identified and classified. Most strongly emphasized were: slums as locations of mostvulnerable populations and objectionable conditions; surface water quality and of course environment and health. 


\section{Figure 5: Rich Picture Development}

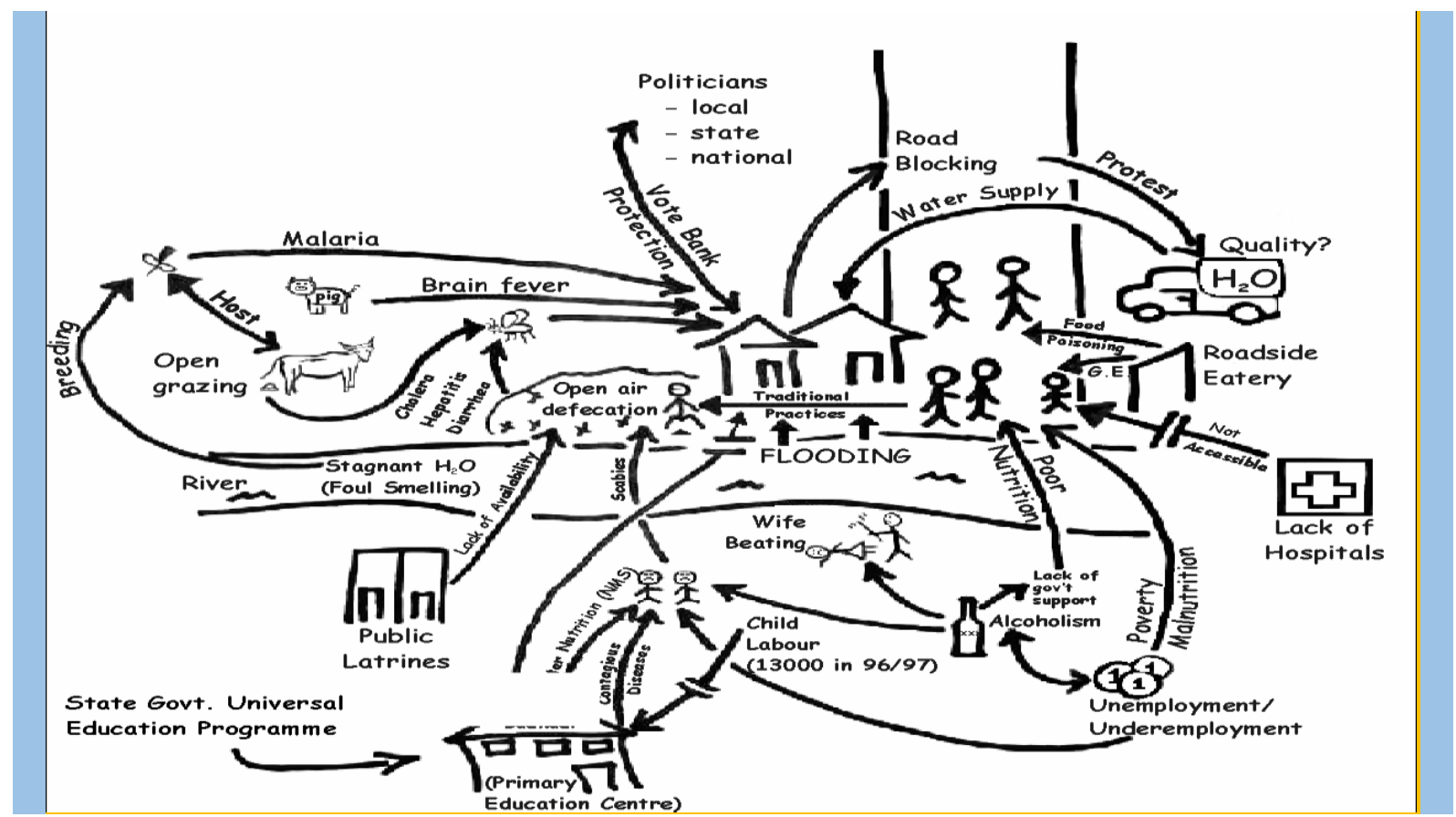

The workshop on environment and health held in Chennai in August 2002 served as a useful instrument to operationalize the ecosystem approach. It brought together stakeholders in the management of environment and health relationships to describe and explore the environment and health situation in Chennai. Participants identified key themes (such as slums as the locations of the most objectionable conditions and vulnerable populations, water quality, malaria and public participation) that the larger research program later addressed. This is one way that the workshop participants helped to direct the research. For example, the York-Madras collaborative research has focused on environment and health in slum areas, with an emphasis on water quality and malaria. We have adopted a participatory approach to this work. The workshop also addressed tools and techniques used within the ecosystem approach (Kumaran et al., 2006; 2012a; 2012b).

But if a paradigm is ever to triumph it must gain some firstsupporters, men who will develop it to the point where hardheadedarguments can be produced and multiplied. And even those arguments, when they come, are not individually decisive, because scientists are reasonable men, one or another argument will ultimately persuade many of them, but there is no single argument that can or shouldpersuade them all.

-Thomas S. Kuhn, the Structure of Scientific Revolutions, Volume II (2): 158.

\section{Conclusion}

I do feel that I have in a way explained how I work on what I do, more especially in collaboration with the people I workwith and with what paradigms. My international colleagues and I have always selected the case-study sites very carefully, often in consultation with each other, although the initial selection was entirely mine. My interest in Theni villages goes as far back as 1984; it goes back even further to 1981 in the case of the Kollihills. Chennai slums and peri-urban Medavakkam are my recent interests, but they have been selected in consultation. My Australian colleagues have helped me validate my 'catchment consciousness' influencing perceptions of places, regional identities, and policies related to sustainable development and regional governance, through the study of sustainable 
communities. In my working with new paradigms and redefining geography for myself, and my colleagues, I am most indebted to colleagues from the Globalism Institute, RMIT University because they are indeed the people who have made me think of my work as that of community engagement in a larger, Local-Global context. I havethus pioneered a form of 'community-engaged research' for geographers to take to, with a commitment to research the same communities over an extended period, that is, beyond the life of any single funded project. I am connecting my work to the theoretical constructs my international colleagues have been developing and they are connecting theirs to those constructs of my work. There is a fusion in the making, I believe for the immense good of geography, which is what I know and do.

\section{References}

1. Bonnett, A. 2003, Geography as the world discipline: connecting popular andacademic geographical imaginations. Area 35, 55-63.

2. Bonnett, A. 2008, What is geography? London: Sage.

3. Bunch, M.J., Franklin, B., Marley, D., Kumaran, T.V., and Suresh, V.M. 2005, Researchin turbulent Environments: Slums in Chennai, India and the Impact of the December 2004 Tsunami on an Ecohealth Project, Profile.EcoHealth2(1-6), 1- 5.

4. Castree, N. 2001, Commodity fetishism, geographical imaginations and imaginative geographies.Environment and Planning A 33(9), 1519-1525.

5. Chang, T. C., and S. Y. Lim 2004, Geographical Imaginations of 'New Asia Singapore'. GeografiskaAnnaler. Series B: Human Geography 86(3), 165-185.

6. Cook, I. et al. 2014. Follow the thing: Papaya. Antipode 48, 642-664.

7. Cook, I., and Crang, P. 1996, Commodity systems, documentary filmmaking and newgeographies of food: Amos Gitai's Ananas'.http://www.gees.bham.ac.uk/downloads/gesdraftpapers/iancook-pineapple.htm.

8. Cosgrove, D. 2006, Geographical imaginations and the authority of the images. Franz Steiner Verlag.

9. Featherstone, M. 1996, Localism, Globalism and Cultural Identity, in R. Wilson and W. Dissanayake (eds): Global-Local, Duke University Press, US.

10. Globalism Institute 2002, Creating Resilient Communities in the context of globalization: A place-based approach to community well-being. A Research Proposal. RMIT University, Melbourne, Australia.

11. Gregory, D. 1995, Between the Book and the Lamp: Imaginative Geographies ofEgypt, 1849-50.Transactions of the Institute of British Geographers 20(1), 29-57.

12. Haggett, P. 1972, Geography: A modern synthesis. London: Edward Arnold.

13. Haggett, P. 1990, The geographer's art. London: Edward Arnold.

14. Hartshorne, R. 1939, Nature of geography. USA: Association of American Geographers.

15. Hartshorne, R. 1959, Perspective on the nature of geography. Chicago: RandMcNally.

16. Harvey, D. 1969, Explanation in geography. London: Edward Arnold.

17. Harvey, D. 1984, On the history and present condition of geography: a historicalmaterialist manifesto. The Professional Geographer 36, 1-11.

18. Johnston, R. J.2003, The institutionalisation of geography as an academic discipline. In R. J. Johnston and M. Williams(editors), A century of British geography.Oxford: Oxford University Press for the British Academy 45-92.

19. Johnston, R. J. 2004, Whose geography? A diversity of definitions, a confusion ofmeanings and the future. Journal of Geography in Higher Education 28, 9-15.

20. Kasbarian, J. A. 1996, Mapping Edward Said: Geography, identity, and the politics of location.Environment and Planning D: Society and Space 14(5), 529-557. 
21. Kumaran, T.V. 2005, Researching local community sustainability in India.Local-Global Studies in Community Sustainability, Hamilton Papers: Community life in the regions.Melbourne: The Globalism Institute, RMIT University, Australia 1, 51-62.

22. Kumaran, T.V., Hyma, B. and Wood, D.M. 2004, Community action planning: Addressing ecological restoration and sustainable livelihoods. Chennai: TR Publications for Shastri Indo-Canadian Institute, New Delhi, India and Calgary, Canada.

23. Kumaran, T. V. and Negi, Elizabeth 2006, Experience of Rural and Urban Communities in Tamil Nadu in the Aftermath of the 2004 Tsunami. Built Environment, 32(4): 375-386.

24. Kumaran, T. V., Rajeswari, S.D., Annammadevi, N., Nandhini, J., Bunch, M.J., Marley, D. and Franklin, B. 2012a, Community Engagement in Chennai Slums. A Reflection from the Field. InternationalesAsien Forum. International Quarterly for Asian Studies. May 43, 1/2: ProQuest 99-113.

25. Kumaran, T. V., Bunch, M.J. and Joseph, R. 2012b, Using Geographic Information Systems (GIS) For Spatial Planning and Environmental Management in India: Critical Considerations. International Journal of Applied Science and Technology 2(2), 40-54.

26. McFarlane, C. 2004, Geographical imaginations and spaces of political engagement: Examples from the Indian Alliance.Antipode 36(5), 890-916.

27. Malpas, J.E. 1999, Place and experience: A philosophical topography.Cambridge, UK: Cambridge University Press.

28. Massey, D. 1994, Space, Place and Gender. Cambridge: Polity Press.

29. Mulligan, M., P. James, C. Scanlon and C. Ziguras 2004, Creating resilient communities: A comparative study of 'Sense of Place' and community well-being in Daylesford and Broadmeadows.Melbourne, Australia: VicHealth.

30. Nadarajah, Y. 2004, The scholarship of community engagement and culture: Learning from the margins, A concept paper, Melbourne, Australia: Globalism Institute, RMIT University.

31. Tomlinson, J. 1999, Globalization and culture. Blackwell: Oxford Printing Press. 